\title{
Monoclonal Antibody CC49-delta CH2
}

National Cancer Institute

\section{Source}

National Cancer Institute. Monoclonal Antibody CC49-delta CH2. NCI Thesaurus. Code C2698.

A humanized $\mathrm{CH} 2$ domain-deleted second-generation monoclonal antibody based on the antibody B72.3 that is directed against tumor-associated glycoprotein 72 (TAG72).

TAG72 is expressed by gastric, breast, pancreatic, colorectal, and ovarian carcinoma cells. ( $\mathrm{NCl04)}$ 